\title{
Acute coronary syndrome as a result of left main coronary artery stenosis after aortic valve replacement. A report of three cases
}

\author{
Aleksander Araszkiewicz' ${ }^{1}$, Maciej Lesiak', Tomasz Urbanowicz ${ }^{2}$, Stanisław Jankiewicz'1, Stefan Grajek ${ }^{1}$ \\ ${ }_{1}^{1}$ st Department of Cardiology, Poznan University of Medical Sciences, Poland \\ 2Department of Cardiac Surgery, Poznan University of Medical Sciences, Poland
}

Postep Kardiol Inter 2013; 9, 2 (32): 150-154 DOI: $10.5114 /$ pwki.2013.35450

\begin{abstract}
Acute coronary syndrome (ACS) as a result of iatrogenic coronary ostial stenosis (ICOS) is a rare but potentially life-threatening complication of aortic valve replacement (AVR). We present three cases of patients with ACS shortly after AVR, in whom ICOS were revealed. They refused an operation and thus they were treated with percutaneous coronary intervention. The potential pathomechanisms of ICOS and treatment options are discussed.
\end{abstract}

Key words: left main coronary artery stenosis, aortic valve replacement, acute coronary syndrome.

\section{Introduction}

Acute coronary syndrome as a result of iatrogenic ostial coronary artery stenosis (ICOS) is a rare but potentially lifethreatening complication of aortic valve replacement (AVR). latrogenic ostial coronary artery stenosis was first described by Roberts and Morrow in 1967 and the incidence of this complication has been estimated as between $0.3 \%$ to $5 \%$ of all AVR procedures [1-6]. Ostial stenosis can occur both in the left main coronary artery (LMCA) and in the right coronary artery (RCA) and may have serious clinical sequelae [1-6]. The symptoms are often severe and may appear within 6 months after an operation. The underlying cause of ICOS still remains undetermined.

We present 3 cases of left main coronary artery stenosis after AVR, describe their clinical presentation and discuss the treatment strategy.

\section{Case reports}

\section{Case 1}

A 70-year-old man was referred with a history of syncope, chest pain, and exertional dyspnoea. Echocardiography revealed aortic stenosis with peak gradient $110 \mathrm{~mm} \mathrm{Hg}$ and aortic valve area (AVA) $0.6 \mathrm{~cm}^{2}$ and severe mitral insufficiency and calcifications. Preoperative coronary angio- graphy (CA) demonstrated normal coronary arteries. In September 2005 the patient underwent aortic and mitral valve replacement. Mechanical prostheses ON-X-19A and ON-X25M (Medical Carbon Research Institute, Austin, TX, USA) were implanted respectively. Cold $\left(4^{\circ} \mathrm{C}\right)$ cardioplegic solution was administered antegrade by means of selective ostial perfusion and use of coronary artery perfusion cannulae in RCA and in LMCA. The patient made a complete recovery and was discharged on oral warfarin. In December 2005 he experienced anginal pain at rest. Admission ECG revealed ST segment elevation in the aVR lead and ST depression and negative T waves in leads V5-V6. Troponin I level was $1.48 \mathrm{ng} / \mathrm{ml}$. Coronary angiography showed isolated severe LMCA stenosis. Echocardiography revealed correct function of both prostheses and left ventricle ejection fraction of $58 \%$. The patient refused reoperation. Percutaneous coronary intervention (PCI) of LMCA with bare metal stent implantation (Muliti-Link Vision $3.5 \mathrm{~mm} \times 15 \mathrm{~mm}$ ) was thus performed (Figure 1). The stent was post-dilated with a non-compliant balloon to $20 \mathrm{~atm}$. The patient was discharged on aspirin, clopidogrel and warfarin and simvastatin, bisoprolol and ramipril. Four months later the patient was admitted because of increasing effort angina. Coronary angiography showed in-stent restenosis in the LMCA. Percutaneous coronary intervention was performed

\section{Corresponding author:}

Aleksander Araszkiewicz MD, $1^{\text {st }}$ Department of Cardiology, Poznan University of Medical Sciences, 1/2 Dluga St, 61-848 Poznan, Poland, tel.: +48 6185492 23, fax: +48 6185490 94, e-mail: aaraszkiewicz@interia.pl

Received: 16.12.2012, accepted: 22.04.2013. 
using an everolimus-eluting stent $(3.5 \mathrm{~mm} \times 23 \mathrm{~mm})$. In intra-vessel ultrasound examination minimal lumen diameter after the procedure was $10.1 \mathrm{~mm}^{2}$. The patient was discharged home on dual antiplatelet therapy and warfarin and he was recommended to maintain INR 2.0-3.0 for 12 months. In 2-year follow-up the patient was asymptomatic.

\section{Case 2}

A 61-year-old male patient with history of arterial hypertension, chronic atrial fibrillation and with normal preoperative CA underwent AVR for calcific aortic stenosis with mean gradient of $52 \mathrm{~mm} \mathrm{Hg}$ (AVA $0.6 \mathrm{~cm}^{2}$ ). An ON-X 21 mechanical prosthesis was successfully implanted in July 2010. Both main coronary vessels were perfused antegradely using soft silicon tip cannulae $(4 \mathrm{~mm}$ and $5 \mathrm{~mm}$, Edwards). Four months later the patient presented with resting angina and heart failure symptoms. His troponin I level was $1.2 \mathrm{ng} / \mathrm{ml}$. Coronary angiography revealed critical LMCA stenosis. The patient rejected re-operation but was amenable to treatment by $\mathrm{PCl}$. The stenosis was crossed with a Balance Middleweight guidewire (Abbot Vascular, Abbot Park, Illinois). A complex PCl using double
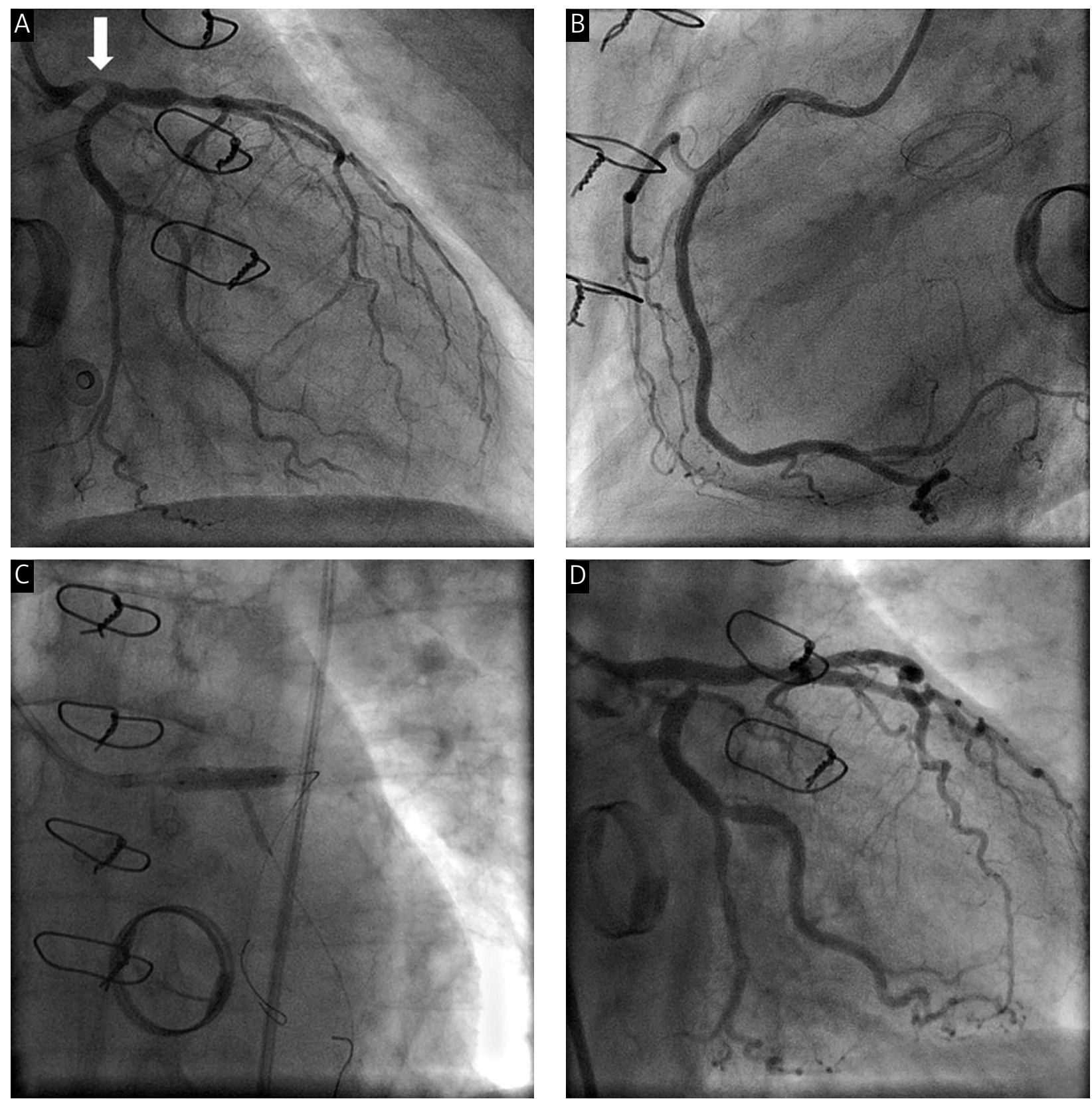

Fig. 1. A - Left main stenosis (white arrow). B - Right coronary artery - no significant changes. C - Percutaneous coronary intervention. Guidewires in left anterior descending and circumflex artery. Bare metal stent was implanted to LM/LAD and final kissing was performed. D - Final view after PCI 
stent technique (T-stenting - zotarolimus-eluting stent Endeavor Resolute, Medtronic, Minneapolis, Minnesota to LMCA-LAD and Endeavour Resolute $3.0 \mathrm{~mm} \times 15 \mathrm{~mm}$ to circumflex) (Figure 2) was successfully performed and 6 months later he was asymptomatic and follow-up CA showed no signs of restenosis.

\section{Case 3}

In August 2010 a 72-year-old man with a history of aortic stenosis underwent AVR and tricuspid valve annuloplasty. A preoperative echocardiogram showed aortic stenosis with peak gradient $80 \mathrm{~mm} \mathrm{Hg}$ (AVA 0.4-0.5 cm²) and significant tricuspid valve insufficiency with dilated annulus $(46 \mathrm{~mm})$. The CA revealed no stenosis in coronary arteries. A $21 \mathrm{~mm}$ mechanical aortic prosthesis (ON-X 21) was implanted and tricuspid annuloplasty was performed. Cold cardioplegic solution was administered antegrade by means of selective ostial perfusion and the use of soft tip cannulae. Six months later the patient presented with unstable angina. Urgent CA revealed ostial LMCA stenosis. Coronary artery bypass graft (CABG) was declined by the patient; therefore urgent $\mathrm{PCl}$ with Biolimus-eluting stent implantation (BioMatrix $3.5 \mathrm{~mm} \times 24 \mathrm{~mm}$, Biosensors Interventional Technologies Ltd., Singapore) was performed with good hemodynamic and clinical results (Figure 3).
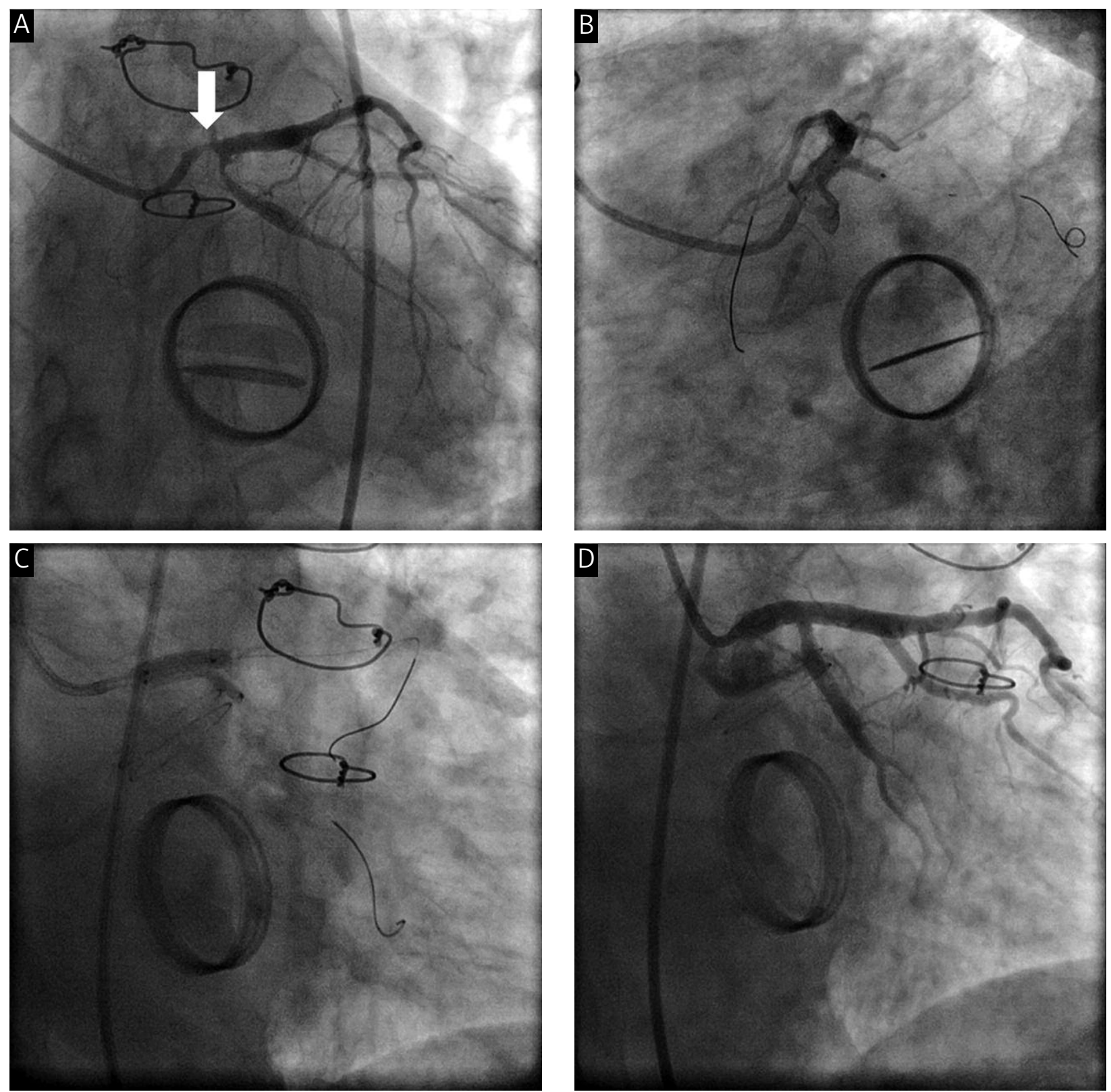

Fig. 2. A - Critical stenosis of LMCA (white arrow). B - Stent implantation in circumflex artery. C - Stent implantation in LMCA/left anterior descending artery with final kissing. D - Final effect after the procedure 

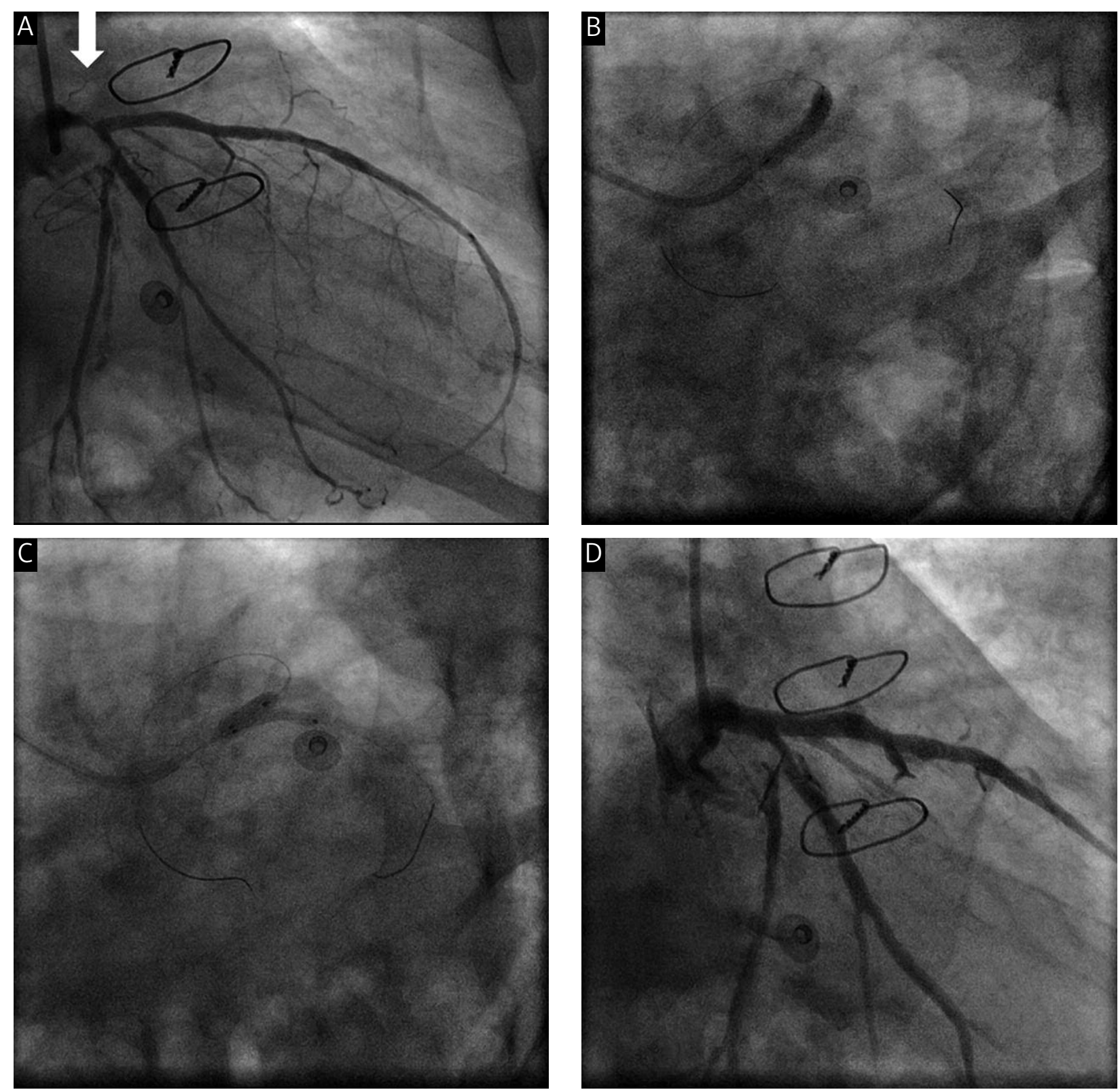

Fig. 3. A - Severe stenosis of LMCA (white arrow). B - Stent implantation in LMCA/left anterior descending artery. $\mathrm{C}$ - Kissing balloon postdilatation. D - The effect of the procedure

\section{Discussion}

Several pathophysiological mechanisms of ICOS have been proposed. The insertion of perfusion cannulae during AVR may produce microinjuries and local hyperplastic reaction due to perfusion pressure of cardioplegic fluid and over-dilation of the vessel by the tip of the catheter [7-9]. There may also be intimal thickening and fibrosis in proximity of the aortic root as a reaction to turbulent flow around the prosthetic valves, leading to obstruction of the coronary ostia. Tukiji et al. reported that immunological reaction to the heterograft in patients with implanted bioprostheses was a potential mechanism of ICOS [7]. Roberts and Morrow showed in autopsy material in patients with
AVR fibrous thickening in the aortic root and proximal coronary artery [1]. Histological examination of a specimen taken by directional atherectomy showed intimal hypertrophy, mucinous degeneration and hyaline degeneration, but no evidence of atherosclerosis [8]. An et al. revealed in multislice computed tomography (MSCT) examination that CT density of ICOS (79.5 Hounsfield units) indicated fibrous tissue [8]. Funanda et al. showed in virtual histology in a patient with ICOS of the left main artery massive fibrous tissue with surrounding slightly arteriosclerotic tissue [9]. They suggested that the slightly calcified layer represented the boundary of the preoperative vessel lumen and that the fibrous and fibrofatty tissue within the calcified layer represented a secondary proliferative fibrotic reaction that 
increased after AVR. These findings showed that ICOS is an in-stent restenosis-like process rather than an atherosclerotic lesion. There may also be a genetic predisposition for developing this complication, since $70 \%$ of affected patients as compared to $10-15 \%$ in a control group had an epsilon 4 allele apolipoprotein E genotype [10].

Avoiding cannulation of the coronary ostia for antegrade cardioplegia but instead using retrograde delivery (through the coronary sinus) as an alternative method for myocardial perfusion may reduce the postoperative risk of ICOS. However, retrograde cardioplegia alone might not be effective in the entire myocardial protection including the right ventricle. Therefore, the best method of cardioplegia still remains unclear $[8,11,12]$.

Chavanon et al. showed that ICOS is associated with high operative mortality and morbidity rates and poor longterm outcome [13]. On the other hand, there are several reports of $\mathrm{PCl}$ with stent implantation treatment in ICOS with good early and late results [5-9]. Despite those good results, some authors recommended that $\mathrm{PCI}$ should only be considered in patients who would otherwise be deemed inoperable or who refused re-operation but were willing to undergo $\mathrm{PCl}$ [12]. However, since most patients with ICOS have acute coronary syndrome and the risk of re-operation is increased, in our opinion, $\mathrm{PCl}$ with drug-eluting stent implantation (due to a lower in-stent restenosis rate) is the best treatment option $[14,15]$.

\section{References}

1. Roberts WC, Morrow AG. Late postoperative pathological findings after cardiac valve replacement. Circulation 1967; 35/36 (Suppl I): 48-62.

2. Lesage CH Jr, Vogel JH, Blount SG Jr. latrogenic coronary occlusive disease in patients with prosthetic heart valves. Am J Cardiol 1970; 26: 123-129.

3. Sethi GK, Scott SM, Takaro T. latrogenic coronary artery stenosis following aortic valve replacement. J Thorac Cardiovasc Surg 1979; 77: 760-767.

4. Pande AK, Gosselin G. latrogenic left main coronary artery stenosis. J Invasive Cardiol 1995; 7: 183-187.

5. Ziakas AG, Economou FI, Charokopos NA, et al. Coronary ostial stenosis after aortic valve replacement. Successful treatment of 2 patients with drug-eluting stents. Tex Heart Inst I 2010; 37: 465-468.

6. Thomopoulou S, Sfirakis P, Spargias K. Angioplasty, stenting and thrombectomy to correct left main coronary stem obstruction by bioprosthetic aortic valve. J Invasive Cardiol 2008; 20: E124-E125.

7. Tukiji M, Akasaka T, Wada N, et al. Bilateral coronary ostaial stenosis after aortic valve replacement with Freestyle stentless bioprosthesis: a case report. J Cardiol 2004; 44: 207-213.

8. An Y, Tamita K, Furukawa Y. latrogenic coronary artery stenosis at the ostium of left anterior descending artery after aortic valve replacement: a case report with imaging and histological findings. J Invasive Cardiol 2010; 22: E206-E208.

9. Funanda A, Mizuno S, Ohsato K, et al. Three cases of iatrogenic coronary ostial stenosis after aortic valve replacement. Circ J 2006; 70: 1312-1317.

10. Winckelmann BR, Ihnken $\mathrm{K}$, Beyersdorf $F$, et al. Left main coronary artery stenosis after aortic valve replacement: genetic disposition for accelerated arteriosclerosis after injury of the intact human artery? Coron Artery Dis 1993; 4: 659-667.

11. Menasche P, Subayi JB, Piwnica A. Retrograde coronary sinus cardioplegia for aortic valve operations: a clinical report on 500 patients. Ann Thorac Surg 1990; 49: 556-563.

12. Gruber S, Ng CK, Schwarz C, Auer J. Unstable angina early after aortic valve replacement surgery in a female patient with normal coronary arteries preoperatively - a case report. J Cardiovasc Surg 2009; 4: 29.

13. Chavanon O, Carrier M, Cartier R, et al. Early reoperation for iatrogenic left main stenosis after aortic valve replacement: a perilous situation. Cardiovasc Surg 2002; 10: 256-263.

14. Park SJ, Kim YH, Lee BK, et al. Sirolimus-eluting stent implantation for unprotected left main coronary artery stenosis: comparison with bare metal stent implantation. J Am Coll Cardiol 2005; 45: 351-356.

15. Park SJ, Kim YH. Percutaneous coronary intervention as an alternative to bypass surgery for unprocected LMCA stenosis. Expert Rev Cardiovasc Ther 2008; 6: 1107-1114. 